\title{
Indigo degradation with purified laccases from Trametes hirsuta and Sclerotium rolfsii
}

\author{
R. Campos ${ }^{\mathrm{a}, \mathrm{b}}$, A. Kandelbauer ${ }^{\mathrm{b}}$, K.H. Robra ${ }^{\mathrm{b}}$, Artur Cavaco-Paulo ${ }^{\mathrm{a}}$, \\ G.M. Gübitz ${ }^{\text {b,* }}$ \\ a Department of Textile Engineering, University of Minho, P-4800 Guimaraes, Portugal \\ ${ }^{\mathrm{b}}$ Department of Environmental Biotechnology, Graz University of Technology, Petersgasse 12, A-8010 Graz, Austria
}

Received 26 June 2000; received in revised form 18 December 2000; accepted 3 January 2001

\begin{abstract}
The degradation of the textile dye indigo with purified laccases from the fungi Trametes hirsuta (THL1 and THL2) and Sclerotium rolfsii (SRL1) was studied. All laccases were able to oxidize indigo yielding isatin (indole-2,3-dione), which was further decomposed to anthranilic acid (2-aminobenzoic acid). Based on the oxygen consumption rate of the laccases during indigo degradation, a potential mechanism for the oxidation of indigo involving the step-wise abstraction of four electrons from indigo by the enzyme was suggested. Comparing the effect of the known redox-mediators acetosyringone, 1-hydroxybenzotriazole (HOBT) and 4-hydroxybenzenesulfonic acid (PHBS) on laccase-catalyzed degradation of indigo, we found a maximum of about $30 \%$ increase in the oxidation rate of indigo with SRL1 and acetosyringone. The particle size of indigo agglomerates after laccase treatment was influenced by the origin of the laccase preparation and by the incubation time. Diameter distributions were found to have one maximum and compared to the indigo particle size distribution of the control, for all laccases, the indigo agglomerates seemed to have shifted to smaller diameters. Bleaching of fabrics by the laccases (based on $\mathrm{K} / \mathrm{S}$ values) correlated with the release of indigo degradation products. (C) 2001 Elsevier Science B.V. All rights reserved.
\end{abstract}

Keywords: Laccases; 1-Hydroxybenzotriazole; Acetosyringone

\section{Introduction}

In the textile finishing industry, enzymatic degradation of indigo could have a potential both in stone-wash process and for the treatment of dyeing effluents. Several steps are involved in the

\footnotetext{
* Corresponding author. Tel.: + 43-316-873-8312; fax: + 43-316-873-8815.

E-mail address: guebitz@ima.tu-graz.ac.at (G.M. Gübitz).
}

manufacture of denim garments between dyeing and the final stone washing where excessive amounts of indigo are removed from the fabrics and discharged with the wastewater.

Over 10000 dyes with an annual production of over $7 \times 10^{5}$ metric ton worldwide are commercially available and $5-10 \%$ of the dyestuffs are lost in the industrial effluents. Color is usually the first contaminant to be recognized in wastewater and a very small amount of dye in water $(10-50$ 
$\mathrm{mg} 1^{-1}$ ) is highly visible and effects the aesthetic merit, water transparency and gas solubility of waterbodies (Chung and Stevens, 1993). Besides the reduction of environmental pollution, enzymatic decolorization of dyeing effluents has recently been shown to enable re-use of the treated water in the dyeing process (Abadulla et al., 2000).

The traditional technology of producing a stone-washed look in denim fabric or jeans involves washing of the fabrics in the presence of pumice to generate the desired localized erosion of the fabrics. Subsequently, fabrics are partially bleached by a treatment with sodium hypochlorite, followed by a neutralization and a rinsing step all causing substantial environmental pollution (Pedersen and Schneider, 1998). Cellulases can partially replace the load of pumice stones having an abrasive effect at the fiber surface producing the stoned-washed look (Cavaco-Paulo et al., 1998). In addition, laccases could bleach indigo dyed denim fabrics to lighter shades.

Laccases (benzenediol:oxygen oxidoreductase, EC 1.10.3.2) are copper containing enzymes that catalyze the oxidation of a range of substances with the concomitant reduction of $\mathrm{O}_{2}$ (Flickinger and Drew, 1999). Laccases are secreted by a great number of white-rot fungi and over 60 fungal strains from various classes have been reported to produce these lignin degrading enzymes (Gianfreda et al., 1999). Laccases catalyze the removal of a hydrogen atom from the hydroxyl group of ortho and para-substituted mono- and poly-phenolic substrates and from aromatic amines by one-electron abstraction, to form free radicals, capable of undergoing further depolymerization, repolymerization, demethylation or quinone formation (Thurston, 1994; Yaropolov et al., 1994; Flickinger and Drew, 1999). The rather broad substrate specificity of laccases with respect to the electron donor may be additionally expanded by addition of redox-mediators, such as ABTS, HBT or compounds secreted by lignolytic fungi, which transfer electrons between the enzymes and the substrates (Bourbonnais et al., 1995; Eggert et al., 1996; Reyes et al., 1999; Wong and Yu, 1999; Johannes and Majcherczyk, 2000).
In this paper, we have studied degradation of indigo both in effluents and on fabrics using purified laccases from Trametes hirsuta and Sclerotium rolfsii in combination with redox-mediators. We will discuss the general principles of laccase-catalyzed reactions of indigo related to the application in the textile industry.

\section{Materials and methods}

\subsection{Enzymes}

T. hirsuta (BT 2566) was grown in a wheat bran based medium and the predominant laccase THL1 (molecular mass: $45 \mathrm{kDa}$ ) was purified as described previously (Goncalves and Steiner, 1996). The laccase THL2 (molecular mass: 60 $\mathrm{kDa}$ ) from $T$. hirsuta was kindly provided by E. Srebotnik from the Vienna University of Technology. S. rolfsii CBS 350.80 was cultivated as described previously (Gübitz et al., 1996) except that konjak glucomannan in the medium was replaced by $0.1 \%(\mathrm{w} / \mathrm{v})$ xylidine and the $55 \mathrm{kDa}$ laccase was purified as described above for THL1.

\subsection{Laccase assay}

Laccase (benzenediol:oxygen oxireductase, EC 1.10.3.2) activity was determined using 2,6dimethoxyphenol (DMP) as a substrate as described before (de Jong et al., 1992). The reaction mixture contained $50 \mathrm{mM}$ sodium malonate $(\mathrm{pH}$ 4.5), $1 \mathrm{mM}$ DMP, $1 \mathrm{mM} \mathrm{MnSO}_{4}$ and $700 \mu \mathrm{l}$ sample in a total of $1 \mathrm{ml}$. The formation of $2,2^{\prime}$, $6,6^{\prime}$-dimethoxydiphenoquinone at $30{ }^{\circ} \mathrm{C}$ was followed spectrophotometrically at $468 \mathrm{~nm}$ and laccase activity was calculated from the molar extinction coefficient $\varepsilon=49.6 \mathrm{mM}^{-1} \mathrm{~cm}^{-1}$ (Wariishi et al., 1992).

\subsection{Preparation of dehydroindigo}

Dehydroindigo was prepared according to the method described previously (Kalb, 1909). Briefly, $1 \mathrm{~g}$ indigo, $5 \mathrm{~g}$ lead dioxide and $2 \mathrm{~g} \mathrm{CaCl}_{2}$ were suspended in $100 \mathrm{ml}$ anhydrous benzene. After addition of $500 \mu \mathrm{l}$ glacial acetic acid, the reaction 
mixture was kept at $60{ }^{\circ} \mathrm{C}$ under stirring until the reaction was finished which was detected by TLC (silica gel, benzene/acetonitrile 2/1). The benzene filtrate was evaporated and the residue was recrystallized from chloroform. The dark red-brown product contained no $\mathrm{N}-\mathrm{H}$ groups according to IR-spectroscopy.

\subsection{Decolorization experiments}

Typically $1 \mathrm{mg}$ of insoluble indigo (BASF) or synthesized dehydroindigo, $500 \mu 1$ enzyme preparation (diluted to give 0.1 nkat $\mathrm{ml}^{-1}$ final laccase activity) and $3.5 \mathrm{ml}$ buffer $(0.1 \mathrm{M}$ sodium acetate, $\mathrm{pH}$ 5.0) in eprouvettes were incubated in a rotary shaker at $30{ }^{\circ} \mathrm{C}$ for various time intervals. All experiments were carried out in triplicates. The indigo degradation products indole-2,3-dione (Sigma) and 2-aminobenzoic acid (Sigma) were quantified using an HPLC apparatus from Kontron, (Neufahrn, Germany, MT2 version 422S) equipped with two high pressure pumps $422 \mathrm{~S}$, a mixer M800, auto-sampler 455, a pre-column $\left(7 \times 4 \mathrm{~mm}^{2}\right)$, a $\left(25 \times 4 \mathrm{~mm}^{2}\right)$ Hypersyl ODS $5 \mu \mathrm{m}$ column from Crom (Herrenbergen, Germany) and a UV detector 430 (2 channels). The mobile phase for the quantification of the indigo degradation products was a degassed mixture of $60 \%$ $(\mathrm{v} / \mathrm{v})$ methanol in water and separated substances were detected at 320 and $400 \mathrm{~nm}$. For the detection of indigo, the dye was dissolved with $\mathrm{K}_{2} \mathrm{Cr}_{2} \mathrm{O}_{7}(0.061 \mathrm{mM})$ under boiling and quantified spectrophotometrically at $441 \mathrm{~nm}$ using calibration curves. Dehydroindigo was quantified dissolving the precipitates in ethanol. UV/VIS-spectra were recorded and peak heights at $440 \mathrm{~nm}$ were compared to the corresponding blanks.

A digital oxygen detection system model 10 (Rankbrothers Ltd., Cambridge, England) equipped with a Clark-type electrode was used for measuring the oxygen consumption during the course of the laccase-catalyzed degradation of indigo. A buffer solution (acetate, $0.3 \mathrm{M}$ ) was saturated with $\mathrm{O}_{2}$ by bubbling air through the solution giving a concentration of oxygen of 0.25 $\mathrm{mM} \mathrm{O}$. Thereafter, $50 \mu \mathrm{l}$ of dye was added to yield a final concentration of dye in the cell of
$0.05 \mathrm{mM}$; the reaction was started by addition of

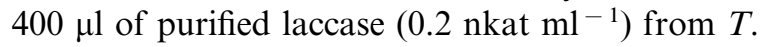
hirsuta (THL1).

\subsection{Adsorption experiments}

$1 \mathrm{mg}$ of indigo was incubated in solutions (25 ml) containing the enzyme preparations from $T$. hirsuta and $S$. rolfsii (diluted to give 0.1 nkat $\mathrm{ml}^{-1}$ final laccase activity) under mechanical agitation on a water bath shaker at $200 \mathrm{rpm}$ and $30{ }^{\circ} \mathrm{C}$ for $20 \mathrm{~h}$. Subsequently, indigo particle size (volume distribution) was measured with a Malvern Mastersizer apparatus (Malvern instruments, Malvern, Worcestershire, UK) based on laser diffraction.

\subsection{Dye removal from the fabric}

Indigo stained fabrics were washed with icechilled buffer ( $\mathrm{pH} 4.85$; acid acetic/NaOH). After $20 \mathrm{~min}$, samples were taken and $46.4 \mathrm{mg}$ indigo/g fabric were added. Washing was continued for a further $20 \mathrm{~min}$. To remove excess of indigo, fabrics were washed for $20 \mathrm{~min}$ in cold water in a commercial washing machine, rinsed and line dried.

Washing experiments were carried out using $100 \mu \mathrm{g}$ of the fabrics stained with indigo. Crude enzyme preparations of THL1 and SRL1 obtained after ammonium sulfate precipitation and ultrafiltration of the culture filtrates diluted to give 0.1 nkat $\mathrm{ml}^{-1}$ final laccase activity, were added and the mixture was incubated in Erlenmeyer flasks on a rotary shaker for $24 \mathrm{~h}$ at $30{ }^{\circ} \mathrm{C}$. After centrifugation, indigo degradation products were quantified with HPLC and insoluble indigo was quantified as described above. Indigo stained fabrics were rinsed and dried and the staining levels $(\mathrm{K} / \mathrm{S})$ were measured at $650 \mathrm{~nm}$ (ACS II Spectrometer).

\section{Results and discussion}

Purified laccases from T. hirsuta (THL1 and THL2) and from $S$. rolfsii (SRL1) degraded indigo yielding isatin (indole-2,3-dione) as an inter- 
mediate, which was further decomposed to give anthranilic acid (2-aminobenzoic acid) as a final reaction product. Isatin as well as anthranilic acid were identified via HPLC analysis and have been reported as indigo oxidation products earlier (Johansen et al., 1997). Laccases contain one 'blue' type 1 copper center (T1), one type 2 copper center (T2), and one type 3 copper center (T3). T1 oxidizes the substrate and transfers electrons to the T2 and T3 sites, which form a trinuclear copper cluster center. In this center, $\mathrm{O}_{2}$ is reduced producing water (Flickinger and Drew, 1999). Free radicals resulting from aromatic amines following one-electron abstraction by laccases can either polymerize or be degraded (Thurston, 1994; Yaropolov et al., 1994).
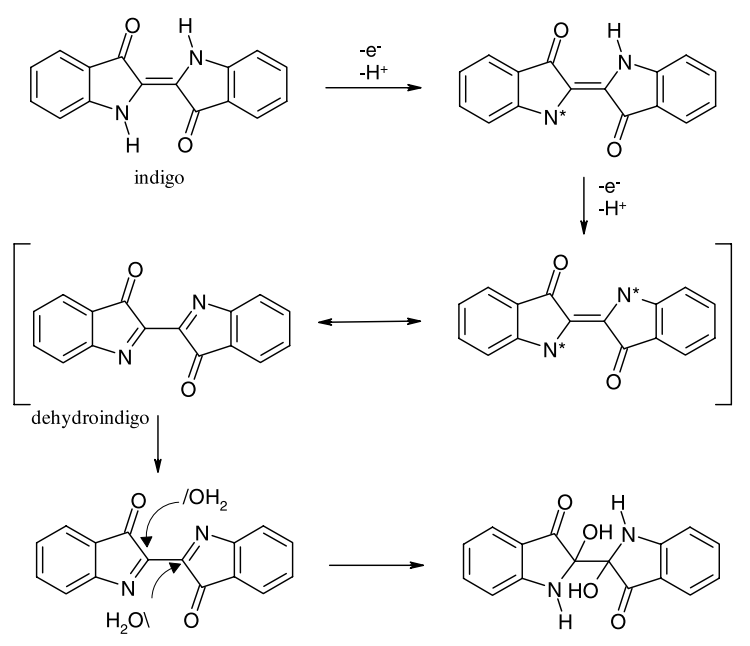

2<smiles>O=C1Nc2ccccc2C1=O</smiles>

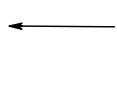

isatin $\downarrow \mathrm{H}_{2} \mathrm{O}$<smiles>Nc1ccccc1C(=O)C(=O)O</smiles>
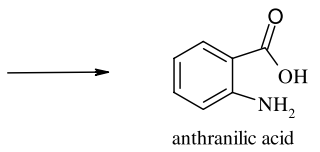

Fig. 1. A possible mechanism for laccase catalyzed degradation of indigo dye.
A possible pathway for the oxidation of indigo to isatin is depicted in Fig. 1. Since the actual catalytic activity of laccases involves the step-wise abstraction of four electrons from the substrate $(\mathrm{Xu}, 1996 ; \mathrm{Xu}$ et al., 2000) it seems logical that the first steps in indigo oxidation proceed analogous to the electrochemical oxidation of indigo carmine, which has been shown to result in the formation of dehydroindigo (Beggiato et al., 1993). This compound may be easily attacked by nucleophiles like water molecules, which leads to the incorporation of O-atoms into the decomposition products actually stemming from the solvent. Dehydroindigo was synthesized and its degradation could be shown to proceed significantly faster in aqueous buffer medium when laccase was present as indicated by the disappearance of absorbance at $440 \mathrm{~nm}$.

We have measured the stoichiometry of the overall reaction by monitoring the consumption of $\mathrm{O}_{2}$ during laccase catalyzed indigo degradation with an oxygen-sensitive electrode. The molar ratio of indigo to molecular oxygen was found to be exactly 1 . Since four electrons are necessary to reduce the $\mathrm{O}_{2}$-molecule to water as well as to oxidize indigo to isatin, our findings imply that in the absence of any other redox-active compound the enzyme should also be involved in the second oxidation step leading to isatin. Detailed studies on the kinetics of indigo oxidation are currently in progress and will be presented later. Once isatin has been formed, further degradation proceeds hydrolytically without mediation of the laccase. The formed intermediate isatic acid is not stable and will decompose spontaneously via decarboxylation yielding anthranilic acid as the final degradation product.

Interestingly, the time course of indigo degradation is similar for both laccases from $T$. hirsuta while the reaction seems to proceed slower in presence of the $S$. rolfsii laccase (Fig. 2). Since all three enzymes were added at the same dose in terms of activity on DMP, obviously the enzymes have different specificities on insoluble indigo.

Several factors may influence the overall velocity of enzymatic indigo degradation such as adsorption phenomena, transport limitations and accessibility and redox potential of the laccase 


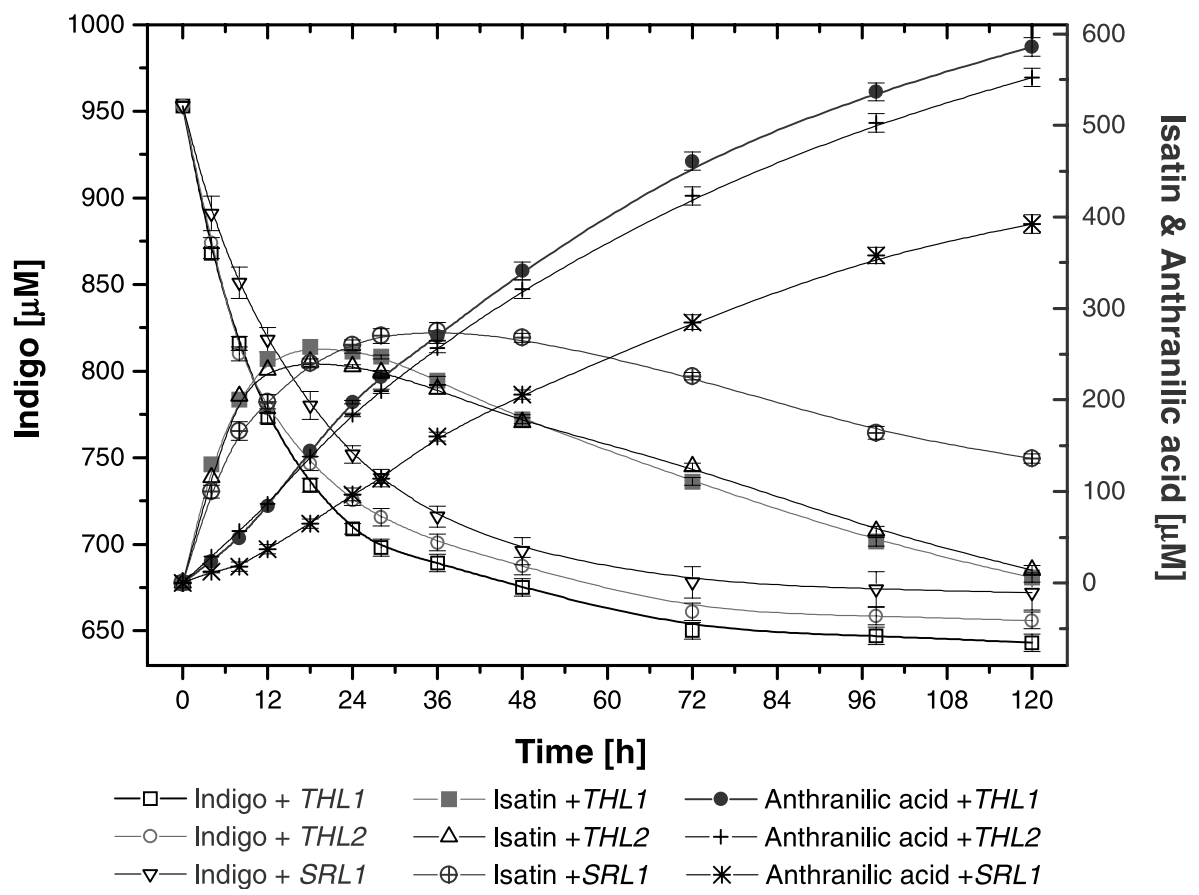

Fig. 2. Degradation of indigo with purified laccases from T. hirsuta (THL1 and THL2) and S. rolfsii (SRL1).

and the substrate. Concerning the latter parameters, the binding sites of laccases for the reducing substrate seem to be quite shallow and thus, steric effects might not influence the oxidation rates (Flickinger and Drew, 1999). Especially for smaller substrates such as indigo, the electronic contribution of substituents on the aromatic ring seemed to be more important than steric effects (Xu, 1996). Thus, rather a higher redox potential of the laccase $\mathrm{T} 1$ site, ranging from 0.4 to $0.8 \mathrm{~V}$ in fungal laccases, will enhance the velocity of the electron transfer from the substrate to the T1 site and the oxidation rate. Electron donating methyl and methoxy substituents seemed to enhance laccase activity while electron withdrawing chloro, fluoro and nitro substituents inhibited oxidation of azophenols and other substituted phenols and phenol analogs by fungal laccases (Chivukula and Renganathan, 1995; Xu, 1996). The oxidation of most substrates by laccases strongly depends on the $\mathrm{pH}$, which is due to two opposing effects. For many substrates such as phenols, the electron transfer rate controlled by the redox potential difference to the T1 site is favored by higher $\mathrm{pH}$ while the binding of hydroxide anions to T2/T3 inhibits the enzyme (Gianfreda et al., 1999). Concluding these facts, the higher oxidation rates measured for the $T$. hirsuta laccases compared to the laccase from $S$. rolfsii for indigo do not necessarily imply a higher redox potential of THL1 and THL2 since this picture might change using other substrates and other reaction conditions (e.g. pH).

The range of substances oxidized by laccases may be expanded by the addition of redox-mediators such as phenoxazines and $\mathrm{N}-\mathrm{OH}$ compounds. After oxidation by laccases to cation radicals, these mediators can oxidize substances with high redox potentials such as non-phenolic lignins, which are otherwise not attacked by the laccase (Bourbonnais et al., 1995; Xu et al., 2000). Interestingly, some fungi have been shown to produce their own low-molecular redox-mediators (Eggert et al., 1996; Wong and Yu, 1999).

Comparing the effect of the known redox-mediators acetosyringone, 1-hydroxybenzotriazole (HOBT) and 4-hydroxybenzenesulfonic acid 
(PHBS) on laccase-catalyzed degradation of indigo, we found a maximum of about $30 \%$ increase in the oxidation rate of indigo with SRL1 and acetosyringone (Table 1). This is not very much compared to increases by more than 20-fold reported for the laccase-catalyzed degradation of azo dyes and indigo carmine using ABTS as a redox-mediator (Wong and $\mathrm{Yu}$, 1999).

Concurrent with the cleavage of indigo molecules into isatin, the THL1 and SRL1 laccase treatment seemed to reduce the particle size of indigo agglomerates (Figs. 3 and 4). Diameter distributions were found to have one maximum and compared to the indigo particle size distribution of the control, for both laccases, the indigo agglomerates seemed to have shifted to smaller diameters. Indigo agglomerates were fractionated into smaller particles when they were incubated with THL1 (Fig. 3), which correlated to the higher indigo oxidation rate of this enzyme. The concentration $(\% \mathrm{v} / \mathrm{v})$ of the particles at the maximum of the distribution seemed to decrease with time due to the degradation of dispersed indigo into soluble products. Thus, binding of laccases to indigo or oxidation of some indigo molecules from the agglomerates may somehow separate agglomerates.

Table 1

Influence of redox-mediators (added in $10 \mu \mathrm{M}$ concentration) on laccase-catalyzed indigo degradation (incubation for $24 \mathrm{~h}$ )

\begin{tabular}{lllll}
\hline & \multicolumn{2}{l}{ Indigo decolorization $($ mean \pm SD) $(\%)$} & PHBS & Without mediator \\
\cline { 2 - 4 } & Acetosyringone & HOBT & $30 \pm 2$ & $25.6 \pm 1$ \\
TH1 & $31 \pm 1$ & $28 \pm 1$ & $28.8 \pm 1$ & $24.9 \pm 2$ \\
TH2 & $30.5 \pm 3$ & $27.1 \pm 2$ & $25.6 \pm 2$ & $21 \pm 1$ \\
\hline
\end{tabular}

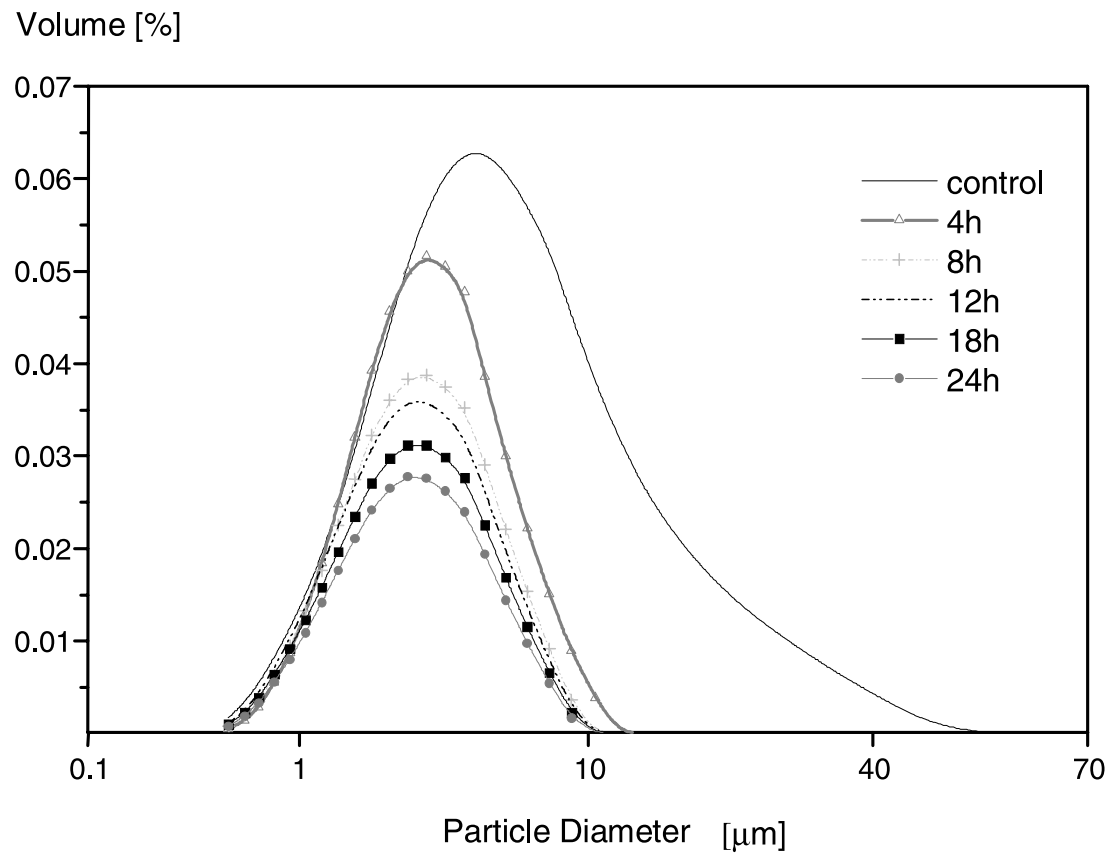

Fig. 3. Particle diameter distribution of indigo incubated with the T. hirsuta laccase (THL1). 
Volume [\%]

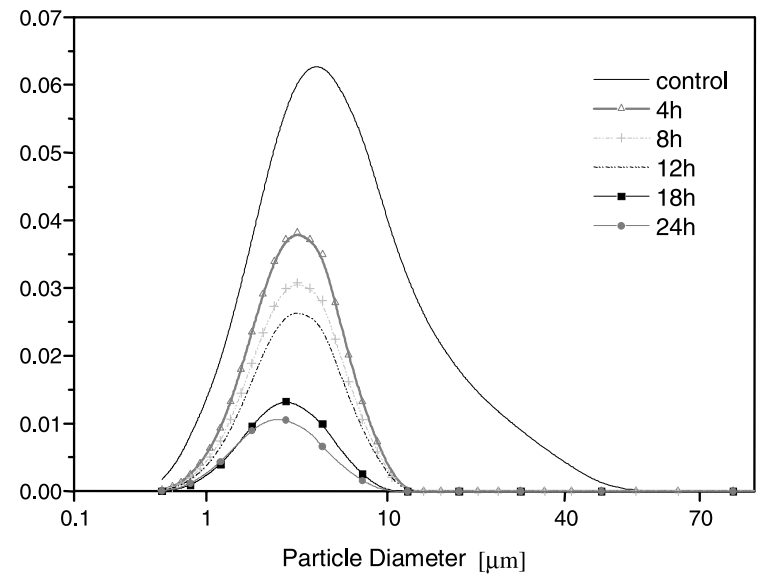

Fig. 4. Particle diameter distribution of indigo incubated with the $S$. rolfsii laccase (SRL1).

The aged look of jeans can be obtained by non-homogeneous removal of the indigo dye trapped inside the cellulose fibers by the cooperative action of cellulases and mechanical action. In this process, the redeposition of removed indigo dye on denim fabrics during washing with cellulases ('backstaining') turned out to be a major

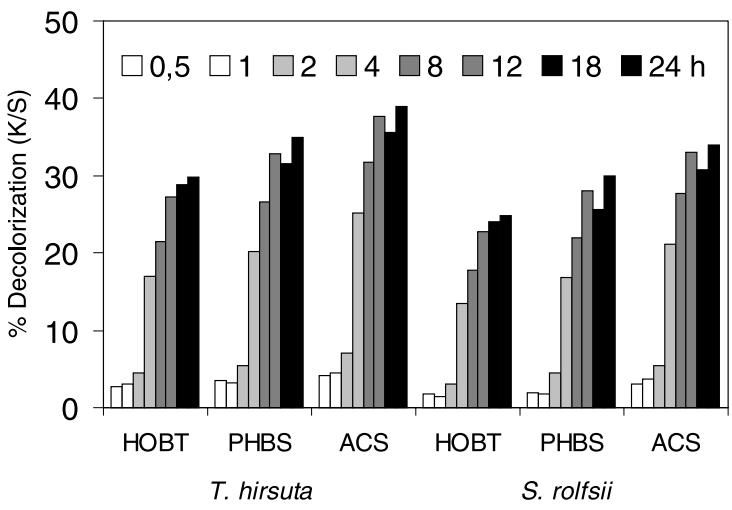

Fig. 6. Bleaching of indigo stained fabrics with enzyme preparations from $T$. hirsuta and $S$. rolfsii in the presence of redox-mediators acetosyringone (ACS), 1-hydroxybenzotriazole (HOBT) and 4-hydroxybenzenesulfonic acid (PHBS). Decolorization was calculated from the $\mathrm{K} / \mathrm{S}$ values.

problem. Enzyme protein or other substances preadsorbed on the fabrics are the major reasons for indigo backstaining and acid cellulases (optimum at $\mathrm{pH}$ 5) had shown more backstaining than neutral cellulases (optimum at $\mathrm{pH}$ 7) (CavacoPaulo et al., 1998). Degradation of indigo, which is released during the stone-wash process could

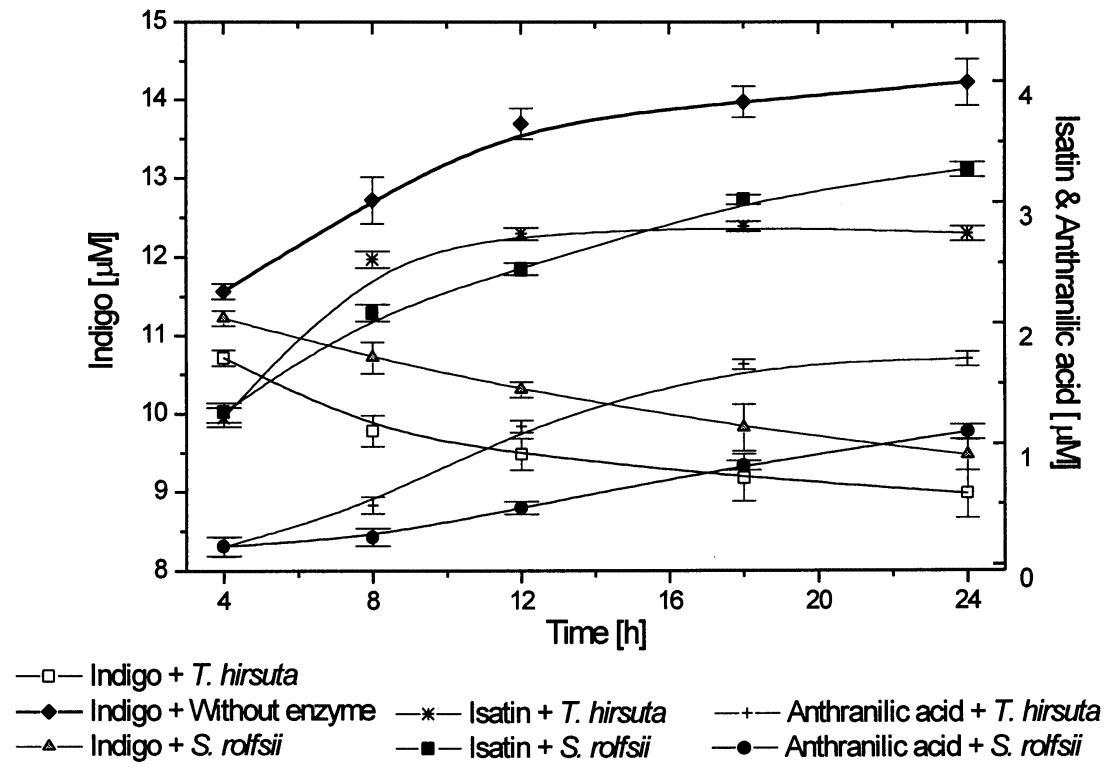

Fig. 5. Indigo degradation products formed from indigo stained fabrics treated with enzyme preparations from $T$. hirsuta and $S$. rolfsii. 
prevent re-deposition of the dye on the fabrics. Incubating indigo dyed fabrics with laccases from $T$. hirsuta or S. rolfsii we were able to produce various bleaching effects to the fabrics. During the laccase treatment also some indigo was released from the fabrics besides isatin and anthranilic acid (Fig. 5). Like for the oxidation of dispersed indigo, the laccase from $S$. rolfsii was less effective in degrading indigo on the fabrics than the enzymes from T. hirsuta (Figs. 5 and 6). Bleaching of the fabrics with the laccases in the presence of mediators quantified with the staining labels $\mathrm{K} / \mathrm{S}$ correlated to the degradation of indigo. Once again, the most pronounced effect of mediators was seen using the $S$. rolfsii laccase in combination with acetosyringone.

Laccase treatment of textile dyes such as indigo, allows selective removal of the color from effluent and thus, reuse of the water and dyeing auxiliaries. Recently, we have shown that enzymatically decolorized textile effluents can be reused within the dyeing process (Abadulla et al., 2000). Furthermore, environmental pollution by textile dyes could be reduced by converting toxic substances such as azo dyes into harmless products (Chivukula and Renganathan, 1995).

Concluding the results of this study, we suggested a potential mechanism for the laccases-catalyzed oxidation of indigo yielding isatin and involving the transfer of four electrons to the enzyme. Concurrently with the oxidation, the particle size of indigo agglomerates is reduced. This laccase-catalyzed reaction, which was enhanced by redox-mediators, could have a potential for the treatment and recycling of dyeing effluents, and to obtain various bleaching appearances in denim garments.

\section{Acknowledgements}

The authors wish to thank T. Tzanov for valuable discussions and the $\mathrm{K} / \mathrm{S}$ measurements.

\section{References}

Abadulla, E., Tzanov, T., Costa, S., Robra, K.-H., CavacoPaulo, A., Gübitz, G.M., 2000. Decolorization and detox- ification of textile dyes with a laccase from Trametes hirsuta. Appl. Environ. Microbiol. 66, 3357-3362.

Beggiato, G., Casalboremiceli, G., Geri, A., Pietropaolo, D., 1993. Indigo carmine an electrochemical study. Ann. Chim. -Rome. 83, 355-363.

Bourbonnais, R., Paice, M.G., Reid, I.D., Lanthier, P., Yaguchi, M., 1995. Lignin oxidation by laccase isozymes from Trametes versicolor and role of the mediator 2,2'-azinobis(3-ethylbenzthiazoline-6-sulfonate) in kraft lignin depolymerization. Appl. Environ. Microbiol. 61, 1876-1880.

Cavaco-Paulo, A., Morgado, J., Almeida, L., Kilburn, D., 1998. Indigo backstaining during cellulase washing. Text. Res. J. 68, 398-401.

Chivukula, M., Renganathan, V., 1995. Phenolic azo dye oxidation by laccase from Pyricularia oryzae. Appl. Environ. Microbiol. 61, 4374-4377.

Chung, K.T., Stevens, S.E., 1993. Degradation of azo dyes by environmental microorganism and helminths. Environ. Toxicol. Chem. 12, 2121-2132.

de Jong, E., de Vries, F.P., Field, J.A., Van der Zwan, R.P., de Bont, J.A.M., 1992. Isolation and screening of basidiomycetes with high peroxidative activity. Mycol. Res. 96, 1098-1104.

Eggert, C., Temp, U., Eriksson, K.E., 1996. Laccase-producing white-rot fungus lacking lignin peroxidase and manganese peroxidase. Acs. Symp. Ser. 655, 130-150.

Flickinger, M.C., Drew, S.W., 1999. Encyclopedia of bioprocess technology: fermentation, biocatalysis and bioseparation. Biocatal. Bioseparation 1545-1554.

Gianfreda, L., Xu, F., Bollag, J.M., 1999. Laccases: a useful group of oxidoreductive enzymes. Bioremediat. J. 3, 1-25.

Goncalves, M.L., Steiner, W., 1996. Purification and characterization of laccase from a newly isolated wood-decaying fungus. ACS Symp. Ser. 655, 258-266.

Gübitz, G.M., Hayn, M., Urbanz, G., Steiner, W., 1996. Purification and properties of an acidic b-mannanase from Sclerotium rolfsii. J. Biotechnol. 45, 165-172.

Johannes, C., Majcherczyk, A., 2000. Natural mediators in the oxidation of polycyclic aromatic hydrocarbons by laccase mediator systems. Appl. Environ. Microbiol. 66, 524-528.

Johansen, S.S., Licht, D., Arvin, E., Hansen, A.B., 1997. Metabolic pathways of quinoline, indole and their methylated analogs by Desulfobacterium indolicum (DSM 3383). Appl. Microbiol. Biotechnol. 47, 292-300.

Kalb, L., 1909. Über dehydro-indigo, ein neues oxidationsprodukt des indigos. I. Ber. Dtsch. Chem. Ges. 42, 3642.

Pedersen, A.H., Schneider, P.t.N.N., 1998. US Pat. 5795855 A. US-Patent.

Reyes, P., Pickard, M.A., Vazquez-Duhalt, R., 1999. Hydroxybenzotriazole increases the range of textile dyes decolorized by immobilized laccase. Biotechnol. Lett. 21, 875-880.

Thurston, C.F., 1994. The structure and function of fungal laccases. Microbiology 140, 19-26.

Wariishi, H., Valli, K., Gold, M.H., 1992. Manganese(II) oxidation by manganese peroxidase from the basidiomycete Phanerochaete chrysosporium. J. Biol. Chem. 267, 23688-23695. 
Wong, Y., Yu, J., 1999. Laccase-catalyzed decolorization of synthetic dyes. Water Res. 33, 35123520.

Xu, F., 1996. Oxidation of phenols, anilines, and benzenethiols by fungal laccases: correlation between activity and redox potentials as well as halide inhibition. Biochemistry 35, $7608-7614$.

Xu, F., Kulys, J.J., Duke, K., Li, K., Krikstopaitis, K.,
Deussen, H.-J.W., Abbate, E., Galinyte, V., Schneider, P., 2000. Redox chemistry in laccase-catalyzed oxidation of N-hydroxy compounds. Appl. Environ. Microbiol. 66, 2052-2056.

Yaropolov, A.I., Skorobogatko, O.V., Vartanov, S.S., Varfolomeyev, S.D., 1994. Laccase properties, catalytic mechanism, and applicability. Appl. Biochem. Biotech. 49, $257-280$. 